\title{
Projeto pedagógico do programa de graduação em Nutrição da Escola de Nutrição da Universidade Federal da Bahia: uma proposta em construção
}

\section{The Pedagogical Project for the Undergraduate Program}

on Nutrition at the Nutrition School, Universidade

Federal da Bahia, Brazil: A proposal in-the-making

Ligia Amparo da Silva SANTOS ${ }^{1}$

Maria da Conceição Monteiro da SILVA ${ }^{1}$

Joselina Martins SANTOS'

Marilena Pacheco ASSUNÇÃO'

Mônica Leila PORTELA ${ }^{1}$

Micheli Dantas SOARES ${ }^{1}$

Maria da Purificação Nazaré ARAÚJO'

Adenilda Queirós SANTOS ${ }^{1}$

Adriana Lima MELO'

Leise Moreira NASCIMENTO²

\section{R E S U M O}

Esse projeto pedagógico fundamenta-se em princípios que estão vinculados a oito eixos educacionais, a saber: perfil profissional, competências, objetivos educacionais, eixos temáticos, organização curricular, estratégias educacionais, sistema de avaliação da aprendizagem e processo de acompanhamento e avaliação do curso. Esses eixos educacionais baseiam-se na prática multiprofissional, bem como na integração do conhecimento, visando à superação das dicotomias: biológico versus social, teoria versus prática, ciclo básico versus ciclo profissional e abordagem individual versus abordagem coletiva. A busca da flexibilização curricular e a utilização de metodologias inovadoras, que visam a uma nova forma de aprender, pautadas na autonomia e independência do aluno, são também elementos centrais do projeto. Para tanto, o aprimoramento científico-

\footnotetext{
1 Comissão de Reconstrução Curricular do Curso de Graduação em Nutrição, Escola de Nutrição, Curso de Nutrição, Universidade Federal da Bahia. R. Araújo Pinho, 32, Canela, 40110-150, Salvador, Bahia, Brasil. Correspondência para/Correspondence to: L.A.S. SANTOS. E-mail: <amparo@ufba.br>.

2 Representante acadêmica na Comissão de Reconstrução Curricular, Curso de Nutrição, Escola de Nutrição, Universidade Federal da Bahia. Salvador, BA, Brasil.
} 
-pedagógico do corpo docente e o processo de avaliação - tanto do curso, quanto dos alunos - também são incorporados ao projeto. Pretende-se socializar esta discussão com vistas a contribuir para o aprimoramento da formação do nutricionista no Brasil.

Termos de indexação: currículo, educação, ensino de nutrição, nutricionista, projeto pedagógico.

\section{A B S T R A C T}

The pedagogical project principles are based on eight educational issues: professional profile, competency, educational strategies, topic issues, curriculum organization, learning assessment system and course evaluation. The fundamental aim of these issues is the integration of knowledge(s), in order to overcome dichotomies such as those of the biological versus the social, the theory versus practice, the basic cycle versus the professional, and the individual approach versus the collective and the multiprofessional practices. The searches for curricular flexibility and methodological innovation imply a new way of learning which is based on the autonomy and independence of the students. Incorporated in the project, as its central elements, are the scientific and pedagogical training of teachers and the course evaluation process. The proposal intends to socialize the discussion, thus contributing to improve the education of nutrition professionals in Brazil.

Indexing terms: curriculum, education, nutrition education, nutricionist, pedagogical project.

\section{N T R O D U Ç Ã O}

Nas últimas décadas, a educação dos profissionais de saúde tem sido profundamente repensada. Isso se deve, em geral, ao processo resultante das mudanças estruturais do mundo contemporâneo nos mais diversos aspectos, destacando-se o político, o econômico, o cultural, o social e o tecnológico. Essas mudanças têm implicado em redirecionamentos nas políticas de educação e de saúde, que, por sua vez, resgatam elementos fundamentais para repensar a educação dos profissionais de saúde.

No âmbito da educação, ressalta-se a reestruturação do ensino superior redimensionando o seu papel de atender às novas demandas sociais, no que tange às evoluções científico-tecnológicas, transformações do mundo do trabalho, bem como ao processo de organização social. Neste sentido, a sociedade demanda profissionais com habilidade para se adaptar a estas constantes mudanças.

A Conferência de Alma Ata foi considerada um importante marco na redefinição das políticas do setor da saúde, assumindo, como princípio fundamental, um processo de reorganização dos serviços de saúde, centrado na Atenção Primária. Desde então, novos temas têm emergido no campo da saúde, tais como o enfoque biopsicossocial e cultural, as novas tecnologias em saúde, a releitura da bioética e o impacto das novas tendências econômicas nas políticas de saúde.

No contexto da alimentação e nutrição, vivencia-se, dentre outros aspectos, o processo de transição alimentar e nutricional, as evoluções tecnológicas, a ênfase na importância da alimentação para a saúde e o conceito de segurança alimentar que, revisitado nos anos 90, reafirma a alimentação como direito humano básico. Esses fatores implicam constantes redefinições das competências necessárias à prática dos profissionais de saúde e, com o surgimento de novas áreas de atuação, exigem novas formas de atuação para o nutricionista'.

Quanto ao processo de formação dos profissionais de saúde, discutem-se as evoluções relativas à educação e à saúde com a clareza da necessidade de mudanças substanciais no processo de formação, sobretudo no que se refere ao perfil profissional desejado e ao modelo pedagógico adotado. Desta forma, preconiza-se maior 
integração entre o mundo do ensino e o do trabalho, ênfase na formação generalista, trabalho multiprofissional, diversificação dos cenários de prática e a adoção de metodologias ativas de aprendizagem. Entretanto, a tradução dessas demandas em conteúdos e atividades curriculares, vem apresentando poucos avanços. As experiências docente-assistenciais têm apontado para esta direção; contudo, a sua incorporação nos currículos formais da área de saúde confronta-se com a rigidez dos modelos curriculares tradicionais ${ }^{1}$.

É nesse amplo contexto que os Cursos de Nutrição estão inseridos. Vários estudos e eventos procuram caracterizar o processo de formação do nutricionista, discutindo, basicamente, o currículo e o perfil profissional desejado. Segundo detectaram esses estudos, nem mesmo o esboço do perfil ideal, o qual ainda está longe de uma definição clara, tem encontrado plena expressão no perfil dos egressos de tais cursos. Identificaram, ainda, como principais problemas curriculares, a existência de um hiato entre os conhecimentos biológicos e sociais, entre a teoria e a prática, como também entre o ciclo básico e o profissionalizante ${ }^{1-4}$.

Vale salientar que, a maioria dos estudos sobre os currículos dos Cursos de Nutrição no Brasil está centrada, basicamente, na comparação dos mesmos, com as recomendações previstas pela Comissão de Estudos para Análise dos Cursos de Nutrição e Dietética para a América Latina (CEPANDAL) e pelo Conselho Federal de Educação (CFE), na década de 70 do século passado. Esses estudos não questionam as limitações daqueles parâmetros, agora defasados, que não preconizam, por exemplo, a adequação das diretrizes pedagógicas dos cursos'1, às novas condições e necessidades da vida contemporânea.

O Curso de Nutrição da Universidade Federal da Bahia (UFBA) vem, ao longo dos seus 44 anos de existência, empreendendo ações no sentido de melhorar continuamente a qualidade da formação profissional. Com essa preocupação, duas grandes reformulações curriculares foram realizadas, uma em 1979 e outra em 1985. A partir de 1990, ajustes contínuos foram efetuados com o intuito de acompanhar, tanto a evolução do conhecimento técnico-científico na área da nutrição e da saúde, como as mudanças no perfil epidemiológico e nutricional.

O currículo do Curso de Nutrição da UFBA, a exemplo dos demais cursos de nível superior do país, se caracteriza pela ênfase no perfil profissional, objetivos e grade curricular; não apresenta, portanto, um projeto pedagógico fundamentado por princípios filosóficos e psicopedagógicos explícitos, necessários à definição das competências, dos objetivos a serem alcançados, das estratégias educacionais e metodológicas e do sistema de avaliação da aprendizagem.

A reconstrução do currículo de graduação em nutrição da Escola de Nutrição da Universidade Federal da Bahia (ENUFBA), considerando as reflexões acima abordadas, culminou num projeto pedagógico cujos referenciais normativos foram: a Lei de Diretrizes e Bases (LDB); as Diretrizes Curriculares para o Curso de Nutrição do Ministério de Educação e Cultura ${ }^{5}$; a Resolução do Conselho Federal de Nutricionistas n 200/1998, assim como a Política de Reconstrução Curricular da UFBA, proposta pela Pró-Reitoria de Ensino de Graduação (PROGRAD) ; e a Resolução n 002/2000, do Conselho de Coordenação desta Universidade ${ }^{7}$.

Além desses referenciais normativos, utilizaram também documentos produzidos pelo Fórum de Pró-Reitores de Graduação ${ }^{8-10}$, documentos de universidades internacionais e brasileiras, referentes ao ensino superior ${ }^{11-13}$, a proposição do projeto pedagógico de Harden ${ }^{14,15}$ e, ainda, as reflexões realizadas pela comunidade acadêmica, evidenciadas e documentadas nos diferentes eventos de avaliação seminários e pesquisas com docentes e discentes, entre outros.

Desse modo, o Projeto Pedagógico foi estruturado levando em consideração oito eixos educacionais, a saber: perfil profissional, competências gerais e específicas, objetivos educacionais, eixos temáticos, organização curricular, 
estratégias educacionais, avaliação da aprendizagem e infra-estrutura de suporte. Pretende-se, no decorrer deste artigo, explicitar os princípios que fundamentam cada um dos eixos citados.

\section{EIXOS EDUCACIONAIS}

\section{Perfil profissional: princípios}

A construção do perfil profissional foi baseada no conjunto das competências necessárias para a formação de um profissional flexível que acompanhe, de forma sistemática e crítica, os permanentes desafios tecnológicos e as mudanças ocorridas na sociedade e no mundo do trabalho. Um profissional que anteveja essas mudanças, e ocupe e amplie espaços, considerando e incorporando princípios humanísticos que valorizem a melhoria da qualidade de vida da sociedade.

Entendendo a formação profissional como um processo contínuo de construção de competências, o futuro profissional deverá ter, como princípio, a educação continuada enquanto um processo permanente que garantirá a sua atuação na sociedade, de forma competente e responsável.

Esse perfil profissional foi construído conforme a apreciação dos perfis, geral e específico, definidos pelas Diretrizes Curriculares Nacionais para os Cursos de Nutrição ${ }^{5}$ (DCNCN) e as especificidades definidas no Projeto Pedagógico do curso de graduação da Escola de Nutrição da Universidade Federal da Bahia.

Nesse contexto, o Curso de Nutrição da UFBA considera como eixos fundamentais para a formação do egresso, desta Instituição, o novo paradigma da atenção à saúde ${ }^{1}$. Nas últimas décadas, tal paradigma, conjugado com o conceito de "segurança alimentar", o qual prevê a alimentação como o direito mais elementar do ser humano, vem sendo construído, permeando a atenção alimentar e nutricional que, enquanto instrumento de trabalho, vê-se respaldada por princípios éticos, humanísticos e pela visão holística do ser humano.

A formação do nutricionista ainda tem, como base, os conhecimentos que se pautam na consideração dos paradigmas explícitos pelas relações de trabalho, os quais, atualmente, se fundamentam nas noções do saber, saber ser, saber fazer e saber conviver, na busca constante do conhecimento, refletindo o compromisso com a qualidade e a competência profissional, a liderança, a capacidade de tomar decisões, e a capacidade de interação e articulação com outros profissionais e com a comunidade.

\section{O perfil profissional do egresso da ENUFBA}

Bacharel em Nutrição, com atuação baseada em princípios ético-humanísticos, detentor de uma visão holística do ser humano, compromissado com a qualidade das ações, que acompanhe, de forma sistemática e crítica, os permanentes desafios científico-tecnológicos e as mudanças ocorridas na sociedade e no mundo do trabalho, antevendo essas mudanças, ocupando e ampliando espaços. Espera-se que a capacidade de tomar decisões, assumir posições de liderança e provocar mudanças, de forma articulada com outros profissionais e a comunidade, tendo na educação continuada o elemento fundamental para a permanente qualificação profissional, sejam também contempladas no processo de formação profissional. O nutricionista deve ser capaz de:

Planejar, executar e avaliar ações e atividades de atenção alimentar e nutricional que envolvam o seu principal objeto de trabalho: a alimentação e nutrição do homem, tendo como meta fundamental a garantia da segurança alimentar, contribuindo para a promoção e recuperação da saúde, prevenção de doenças e, conseqüentemente, a melhoria da qualidade de vida do indivíduo e da coletividade $^{18}$. 


\section{Competências gerais e específicas: princípios}

Entende-se como competência a capacidade do profissional de integrar conhecimentos, habilidades e atitudes a serem aplicados em sua vida profissional. Para a elaboração deste eixo educacional, considerou-se as competências e habilidades definidas nas Diretrizes Curriculares para os cursos de graduação em Nutrição, tomando-se também como referência o documento elaborado pelo Conselho Federal de Nutricionistas, "Definições e atribuições principal e específicas dos nutricionistas, conforme áreas de atuação", e a Lei no 8234, de 17/09/1991, que regulamenta a profissão do nutricionista ${ }^{16}$. As competências gerais e específicas delineadas para o Curso de Nutrição da ENUFBA encontram-se no Anexo 1.

\section{Objetivos educacionais: princípios}

Os objetivos educacionais (Anexo 2), estão baseados nas competências gerais e específicas necessárias para o desempenho do nutricionista, apontadas pelo perfil profissional, englobando as dimensões do conhecimento, habilidades e atitudes a serem apreendidas.

\section{Eixos temáticos: princípios}

Os eixos temáticos, não mais interpretados como uma listagem de disciplinas tradicionais, constituem um conjunto integrado de tópicos curriculares relacionados às competências exigidas do profissional. Considerando os princípios de interdisciplinaridade e flexibilidade curricular, decidiu-se não dividir os conteúdos em básicos e específicos, conforme sugerem as Diretrizes Curriculares do Curso de Graduação em Nutrição.

Optou-se, então, por organizar os eixos temáticos partindo do geral para o particular, compreendendo a realidade como um todo que integra todas as dimensões das partes, numa interpelação constante, dinâmica e paradoxal. Em outras palavras, parte-se do homem social para o biológico.

Cada eixo temático constitui-se de temas curriculares cuja seleção respeitou os critérios de pertinência, complexidade crescente, continuidade e significância para a formação do profissional.

Cabe ressaltar que o primeiro eixo temático - denominado como elementos essenciais que permeiam o processo de formação do nutricionista - refere-se ao conjunto de conceitos, conteúdos e instrumentos essenciais que devem ser trabalhados, de forma transversal, durante todo o processo de formação. Esses temas devem ser operacionalizados, tanto por intermédio de um ou mais componentes curriculares específicos, como também ao longo do curso, de forma contínua e progressiva, envolvendo todo o corpo docente, a exemplo da ética e da atitude científica. Os eixos temáticos definidos para o Curso de Nutrição da ENUFBA são apresentados no Anexo 3.

\section{Organização curricular: princípios}

A matriz curricular é o espaço no final o conhecimento deve ser sistematizado e organizado, de forma ágil e flexível, de forma a reduzir os limites entre o mundo do ensino e do trabalho. Essa construção deve atender aos princípios da flexibilidade, integração e autonomia do aluno no seu processo de aprendizagem.

O currículo que está sendo proposto contempla um conjunto de componentes curriculares nucleares - os obrigatórios, englobando os conteúdos centrais para a formação; os componentes curriculares complementares gerais, relacionados à formação geral, assim como os componentes opcionais e os de aprofundamento. Estes últimos possibilitam maior participação do aluno na definição dos seus estudos, de acordo com sua área de interesse, respeitando, desta forma, o "princípio da flexibilidade". Estratégias para a promoção da integração horizontal (organização dos conteúdos em ordem de complexidade) e vertical (interdisciplinaridade dos conteúdos) também estão sendo construídas. 
Considera-se como fundamental na organização curricular a diversificação dos cenários de prática, os quais devem possibilitar o "aprender fazendo" nos campos de atuação profissional, ou seja, a aprendizagem baseada em realidades e situações concretas, em contraposição a situações hipoteticamente ideais desde o início do processo de formação.

Recursos estão sendo utilizados a fim de possibilitar a superação das dicotomias: biológico x social, teoria $x$ prática, ciclo básico x profissional, abordagem individual $x$ coletiva, historicamente citadas como problemas existentes nos currículos dos cursos de nutrição. Vale salientar que estas questões não são meros problemas quantitativos a serem superados pela ampliação da carga horária e/ ou inclusão de disciplinas .

O problema tem origem na própria estrutura curricular, baseada no modelo Flexneriano datado do começo do século passado e adotado nos cursos da área de saúde, este é um modelo de saúde biologicista, individualizado, com ênfase nas ciências básicas e na prática curativa ${ }^{17}$. Na concepção de construção do conhecimento que orienta os currículos de ensino superior, permeia, ainda, a influência da cosmovisão positivista, a qual compreende a organização do conhecimento de uma forma linear, do teórico para o prático e do ciclo básico para o profissionalizante. Essa concepção, em termos pedagógicos, pressupõe que o aluno precisa dominar a teoria para depois aplicá-la, não incluindo, portanto, a prática como espaço de construção da aprendizagem.

\section{A matriz curricular}

A matriz curricular proposta parte dos eixos temáticos nos quais os objetivos são ampliados progressivamente quanto à sua complexidade, possibilitando a integração vertical entre os diferentes componentes curriculares. Os componentes curriculares abordam um tema central como eixo norteador, orientando o atendimento ao princípio da integração horizontal. Ainda para atender ao princípio da integração foi proposto um componente curricular integralizador, em cada semestre, que objetiva fortalecer esse processo. Para tanto, se faz necessária a utilização de propostas metodológicas inovadoras, a exemplo da metodologia de aprendizagem baseada em problemas ${ }^{15}$, vinculadas à atuação prática, à pesquisa e à extensão.

Em conseqüência, um importante componente curricular foi proposto: a prática em comunidades desde o início do curso, para que o aluno faça o contato com a realidade social, integrando-a à sua prática profissional. Tal prática será organizada a partir dos campos de atuação do nutricionista, considerando o processo de organização dos serviços de saúde em termos de complexidade, das ações da atenção primária, às da atenção terciária. Esta organização beneficiará, tanto ao futuro profissional, possibilitando-lhe compreender a realidade como um todo, como à instituição educadora, permitindo-lhe direcionar a formação do nutricionista de forma a contemplar o perfil definido no Projeto Pedagógico. Estes cenários de práticas obedecem também a uma hierarquia de conhecimentos e à organização do sistema de saúde nos diversos níveis de atenção.

A flexibilidade curricular é princípio fundamental, uma vez que possibilita aos alunos construírem o seu percurso curricular; contudo, como é um princípio difícil de ser implementado, as estratégias consideradas para garanti-lo, foram: a diminuição dos pré-requisitos, a oferta de componentes curriculares complementares de formação geral, específica e de aprofundamento, assim como o aproveitamento de atividades extracurriculares.

\section{Estratégias educacionais: princípios}

A nova proposta do Curso de Nutrição da ENUFBA centra-se em estratégias metodológicas que enfatizam a construção/produção do conhecimento, ao invés da transmissão e da aquisição das informações. Conseqüentemente, o programa procura reduzir progressivamente as 
metodologias demonstrativas (a exemplo das aulas expositivas), dando espaço às diversificações didáticas e pedagógicas que privilegiem instrumentos de aprendizagem, tais como a pesquisa e a extensão, estimulando a atitude científica. O processo de ensino-aprendizagem centra-se no estudante, priorizando sua autonomia e responsabilidade diante do seu próprio aprendizado.

O Projeto prescreve, portanto, a atenção especial ao componente prático do curso, ou seja, às práticas em comunidade, consideranda contudo, a dificuldade de sua implementação, devido à ausência de propostas didática e pedagógica voltadas para este propósito. Procura também, substituir a lógica da prática profissional idealizada, de caráter demonstrativo, do "como deve ser", tal como é ensinada na graduação, por uma lógica de prática profissional atualizada, de "como ela é e como pode ser modificada" - uma prática de caráter crítico que seja, portanto, construtiva do conhecimento.

A ênfase na interdisciplinaridade e no trabalho multiprofissional pressupõe a adoção de metodologias que utilizam trabalhos em grupo e que incentivam a aprendizagem colaborativa.

\section{Avaliação da aprendizagem: princípios}

Atualmente, a avaliação do desempenho dos alunos, em geral, é realizada isoladamente, por cada disciplina, segundo critérios exclusivos de cada professor; cuja avaliação trabalha basicamente com a dimensão do conhecimento do aluno. Neste caso, não há uma avaliação global do progresso do aluno ao longo do curso, nem se dispensam às suas habilidades e às suas atitudes a atenção que merecem, já que constituem, elementos fundamentais para o desempenho das competências esperadas.

Dessa forma, esta proposta adota um sistema de avaliação processual e contínuo, que valoriza o monitoramento da aquisição e utilização dos conhecimentos, habilidades e atitudes, além da avaliação credencial, a qual certifica que o aluno alcançou os objetivos estabelecidos no curso.

Essas estratégias visam a auxiliar os estudantes, tanto na avaliação de seu próprio desempenho, reconhecendo seus alcances e limites, como na clareza das metas a serem alcançadas. Vale salientar, também, a importância da auto-avaliação para a formação de atitudes que estimulem a capacidade de autocrítica.

\section{Processo de acompanhamento e avaliação do curso}

O acompanhamento e a avaliação dos processos curriculares não têm recebido o devido destaque. Trata-se de uma etapa fundamental, tanto para diagnosticar se as metas e objetivos estabelecidos pelo curso foram alcançados, como para fornecer elementos para o redirecionamento do projeto curricular. O projeto contempla o posterior estabelecimento de critérios, quantitativos e qualitativos, que focalizem não só o produto, mas também o processo, e possibilitem a identificação das metas alcançadas.

\section{N F R A-E S T R U T U R A D E S UPORTE PARA I M PLANT AÇÃ O DO PROJETO PE D A G Ó G I CO}

\section{Capacitação do corpo docente}

O projeto busca estimular o corpo docente a se qualificar, não só nas áreas de conhecimento relacionadas aos programas de pós-graduação, mas também nas de programas específicos. O corpo docente deve aprimorar sua competência científico-pedagógica, com ênfase no ensino superior, via cursos formais, tais como os de especialização, ou por meio de atividades contínuas, tais como oficinas, workshops e outros, que proporcionem o avanço constante no diálogo pedagógico entre os docentes. Essas estratégias visam possibilitar não só mudanças metodológicas 
na prática docente, mas, sobretudo, uma nova concepção da formação profissional.

\section{Suporte ao corpo discente}

A implantação de um novo projeto pedagógico, que prevê um redimensionamento da relação aluno-professor, aluno-aluno e aluno-aprendizagem, no qual os princípios da autonomia e independência no aprender são considerados, representa um choque e estabelece uma ruptura com as formas tradicionais em que $o$ aluno vem construindo a sua formação. Tal perspectiva demanda um investimento a fim de preparar os alunos para este novo desafio. Esta proposta pode ser desenvolvida de duas formas: uma, inserida nos próprios componentes curriculares, nos quais todo o corpo docente deve estar trabalhando uma nova perspectiva do aprender; outra, inserida em projetos/momentos específicos, tais como cursos que possibilitem ao aluno compreender as novas demandas feitas em relação ao seu papel no processo de aprendizagem.

Além das atividades já em curso, como o Projeto de Orientação Acadêmica, outras possibilidades, tais como a construção de um manual de orientação ao aluno sobre o processo curricular, devem ser avaliadas e podem ser aplicadas.

\section{CONSIDERAÇÕES FINAIS}

Os primeiros ensaios para a elaboração de uma proposta curricular surgiram nos meados dos anos 90, a partir de reflexões sobre a prática pedagógica. Vivências, palestras, cursos e oficinas, suscitaram questionamentos sobre o currículo em vigência. Tais processos foram estimulados pelo Projeto UNI (Uma Nova Iniciativa na Educação dos Profissionais de Saúde: União com a Comunidade), financiado pela Fundação Kellogg. Este foi implementado na UFBA, com o propósito de redirecionar a formação dos profissionais de saúde, integrando serviços de saúde, comunidade e ensino. Como conseqüência, criou-se uma Comissão de Reconstrução Curricular.
Um dos princípios assumidos pela Comissão para a elaboração do Projeto Pedagógico foi a sua construção coletiva. Ou seja, assumiu-se que uma proposta curricular só seria viável se houvesse envolvimento de todo o corpo docente, em todas as fases do processo de reconstrução; tal envolvimento, por sua vez, ampliaria a responsabilidade coletiva em relação ao projeto.

Assim, a Comissão realizou uma série de oficinas e reuniões, com o intuito de desencadear o processo de construção coletiva. A primeira Oficina, na qual foi apresentado o Projeto inicial, contou com a participação, tanto dos docentes e discentes da ENUFBA, e docentes convidados de outras instituições que estavam realizando reformas curriculares, como de representantes de associações e do Conselho Regional de Nutrição.

Foram realizadas outras oficinas com abordagens metodológicas diversas; no entanto, os trabalhos em grupos predominaram. Atividades de capacitação na área educacional foram também realizadas, uma vez que mudanças de concepções sobre ensino-aprendizagem eram prementes.

Inúmeros problemas têm sido enfrentados, a saber: a) as sucessivas greves que a Universidade vivenciou neste período ocasionaram descontinuidades no processo; b) a infra-estrutura da Universidade que, além da carência de recursos materiais, humanos e financeiros, conta ainda com uma tradicional estrutura organizacional a qual não contribui para a implementação de projetos inovadores; c) a falta de capacitação dos docentes na área educacional, para a construção de uma proposta inovadora.

Vale salientar que, neste mesmo período, a UFBA, respondendo à política de reformulação do ensino superior, construiu uma proposta de reestruturação curricular dos cursos de graduação, que veio a convergir com os propósitos vivenciados na ENUFBA.

No presente momento, com a proposta inicial aprovada pela comunidade acadêmica da 
ENUFBA, a Comissão prossegue com as discussões no que tange à construção da matriz curricular a ser implementada, tendo em vista a concretização possível do projeto. Evidentemente, o grau de avanços nessa direção depende das condições concretas, em termos de infra-estrutura e capacitação pedagógica dos docentes; portanto, pode-se considerar esse projeto uma imagemobjetivo, a ser alcançada por intermédio da avaliação processual e do conseqüente ajustamento das estratégias utilizadas.

\section{RE FER Ê N C I A S}

1. Santos LAS. The Education of Nutrition Professionals in Brazil: an evaluation [dissertation]. Dundee-Escócia: Center for Medical Education, University of Dundee; 1999.

2. Associação Brasileira de Nutrição. A formação do nutricionista no Brasil: sinopse de estudos e diagnósticos realizados nas três últimas décadas. Brasília; 1992.

3. Associação Brasileira de Nutrição. Seminário de Formação em Nutrição no Brasil; ênfase na Graduação. Relatório Final de Workshop. Salvador;1987.

4. Costa NMS. Currículo e formação profissional: as reformulações curriculares dos cursos de Nutrição [dissertação]. Goiânia: Universidade Federal de Goiás; 1966.

5. Brasil. Ministério da Educação e Cultura. Departamento de Política do Ensino Superior. Diretrizes curriculares para o Curso de Graduação em Nutrição. Brasília; 1999.

6. Pró-Reitoria de Ensino de Graduação da UFBA. Política de Reestruturação dos Currículos dos Cursos de Graduação da UFBA. Proposta aprovada pela Câmara de Ensino de Graduação em 7/10/1999. Salvador; 1999

7. Universidade Federal da Bahia. Conselho de Coordenação. Resolução 002/2000. Salvador; 2000.

8. Fórum de Pró-Reitores de Graduação das Universidades Brasileiras. Do pessimismo da razão para o otimismo da vontade: referências para a construção dos projetos pedagógicos nas IES brasileiras. Texto elaborado a partir da Oficina de Trabalho de Curitiba. Curitiba; 1999.

9. Fórum de Pró-Reitores de Graduação das Universidades Brasileiras. O Currículo como expressão do projeto pedagógico: um processo flexível. Texto elaborado a partir da Oficina de Trabalho de Niterói. Niterói; 2000.

10. Fórum de Pró Reitores de Graduação das Universidades Brasileiras. Plano Nacional de Graduação: um projeto em construção. Ilhéus; 1999.

11. Universidade de Caxias do Sul. Pró-Reitoria de Graduação. Coordenadoria de Avaliação e Qualificação. Projeto Pedagógico: subsídios para elaboração e avaliação. Caxias do Sul: EDUCS; 1999. 63p.

12. General Medical Council. Tomorrow's doctors: Recommendations on Undergraduate Medical Education. London; 1993.

13. United Nations Educational, Scientific and Cultural Organization. Higher Education in the Twenty-First Century: Vision and Action. World Conference on Higher Education. Paris; 1998.

14. Harden RM, Davis M. The Core Curriculum with Options or Special Study Modules: Education Guide. Dundee, Escócia: AMEE; 1995.

15. Harden, RM. Ten questions to ask when planning a course or curriculum. Med Educ. 1986; 20(4):356-65.

16. Conselho Federal de Nutricionistas. Definições e atribuições principais e específicas dos nutricionistas, conforme áreas de atuação. Salvador; 1996.

17. Marsiglia R. Relação Ensino/Serviço: dez anos de integração docente assistencial (IDA) no Brasil. São Paulo: Hucitec; 1995.

18. Colegiado de Curso de Nutrição. Escola de Nutrição. Universidade Federal da Bahia. Proposta do Projeto Pedagógico do Curso de Graduação em Nutrição da ENUFBA. Salvador; 2000.

Recebido para publicação em 12 de maio de 2003 e aceito em 5 de abril de 2004 


\section{ANEXO 1}

\section{COMPETÊNCIAS GERAIS E ESPECÍFICAS PROPOSTAS PARA O CURSO DE NUTRIÇÃO DA ENUFBA}

\section{Competências gerais}

1. Aplicar técnicas de comunicação e de relações humanas que permitam adequada relação com o paciente, comunidade e equipe multiprofissional;

2. Utilizar a informática como instrumento de trabalho;

3. Exercer domínio das línguas inglesa e espanhola que possibilite o acesso à produção científica da área;

4. Assumir posições de liderança e tomar decisões;

5. Realizar o trabalho dentro do mais alto padrão de qualidade e princípios da ética;

6. Ter capacidade crítica, analítica e reflexiva;

7. Ter responsabilidade social e compromisso com a construção da cidadania;

8. Superar as barreiras culturais, sociais e pessoais na interação com os pacientes, grupos e comunidade;

9. Ter espírito empreendedor;

10. Incorporar a educação continuada como princípio de qualificação profissional;

11. Participar do planejamento e da gestão dos recursos econômicos e financeiros nas diferentes áreas de atuação;

12. Integrar e atuar em equipe multiprofissional de saúde;

13. Prestar consultoria na área de Alimentação e Nutrição.

\section{Competências específicas}

1. Planejar e avaliar projetos para as unidades de alimentação e nutrição tais como as instalações físicas, equipamentos e utensílios;

2. Planejar, implantar, organizar, gerenciar e avaliar todas as etapas dos processos de produção e distribuição de refeições;

3. Exercer o controle de qualidade dos alimentos em sua área de competência;

4. Desenvolver e avaliar novas fórmulas ou produtos alimentares visando sua utilização na alimentação humana;

5. Realizar a avaliação alimentar e/ou nutricional em indivíduos e coletividades;

6. Planejar e atuar em políticas e programas de alimentação e nutrição;

7. Exercer a vigilância alimentar e nutricional (produção, armazenamento e comercialização, distribuição e utilização biológica dos alimentos);

8. Atuar na formulação e execução de programas de vigilância sanitária dos alimentos;

9. Realizar o planejamento alimentar e nutricional de acordo com as demandas da clientela: no âmbito individual, familiar e coletivo;

10. Planejar, prescrever, analisar, supervisionar e avaliar dietas e suplementos dietéticos para indivíduos;

11. Desenvolver atividades relacionadas à seleção, recrutamento e programas de capacitação dos recursos humanos;

12. Planejar e desenvolver programas e ações de educação alimentar para indivíduos, grupos específicos e coletividades;

13. Desenvolver estudos e pesquisas na área de Alimentação e Nutrição;

14. Colaborar na formação de profissionais da área de Saúde e Nutrição;

15. Assessorar no planejamento, implantação e avaliação de programas e serviços na área de Alimentação e Nutrição;

16. Planejar, executar e avaliar atividades didático-pedagógicas na área de Alimentação e Nutrição para o ensino fundamental, médio e os cursos de graduação em nutrição e outras áreas afins;

17. Atuar em marketing em alimentação e nutrição. 


\section{ANEXO 2}

OS OBJETIVOS EDUCACIONAIS PROPOSTOS PARA O CURSO DE GRADUAÇÃO EM NUTRIÇÃO DA ENUFBA

No domínio do conhecimento - ao final do curso de graduação, o aluno deverá estar capacitado a:

- Compreender as bases conceituais dos princípios humanísticos, éticos e bioéticos; das relações interpessoais; comunicação e informação, auto - cuidado, princípios e métodos da ciência, tecnologia e processo de trabalho.

- Compreender os conceitos centrais envolvidos na prática profissional: saúde; processo saúde e doença; segurança alimentar; atenção à saúde; e atenção alimentar e nutricional.

- Compreender a relação homem e alimento nas suas múltiplas dimensões: sociais, econômicas, culturais, políticas, antropológicas, psicológicas, sociológicas e biológicas, via:

1. Processo de produção, distribuição e utilização biológica dos alimentos;

2. Comportamento alimentar e os seus determinantes;

3. Composição, propriedades e transformações dos alimentos;

4. Processo(s) tecnológico(s) aplicado(s) ao preparo, armazenamento, processamento, controle, conservação, embalagem, distribuição e utilização dos alimentos e produtos alimentícios;

5. Impacto sobre o valor nutritivo dos alimentos, biodisponibilidade, inocuidade e suas consequências para a saúde humana;

6. Estudo dos diversos estágios fisiológicos e demais grupos específicos (atletas, trabalhadores);

7. Estudo do processo saúde doença nos diversos estágios fisiológicos e demais grupos específicos (atletas e trabalhadores);

8. Processo de digestão, absorção, metabolismo e excreção, bem como as funções dos nutrientes e outros componentes alimentares no organismo humano;

\section{Conhecer as principais formas de investigação e detecção dos problemas de saúde e de nutrição que afetam os indivíduos e a população, por meio de:}

1. Conceitos, métodos e técnicas da investigação epidemiológica em saúde e nutrição;

2. Conceitos, métodos e técnicas de avaliação alimentar e nutricional no plano individual e coletivo;

\section{Conhecer as principais formas preconizadas de intervenção nos problemas de saúde, alimentação e nutrição para as populações e indivíduos, por meio de:}

1. Teorias, enfoques e métodos das políticas, estratégias e ações de saúde, bem como de alimentação e nutrição, historicamente construídas para o enfrentamento dos problemas;

2. Os elementos constitutivos do novo modelo da atenção à saúde preconizados para o enfrentamento dos desafios atuais;

3. Métodos e técnicas de administração e gerenciamento das ações de saúde e nutrição bem como de serviços de alimentação e nutrição;

4. Princípios, métodos e técnicas da atenção alimentar e nutricional aplicada aos diferentes estágios fisiológicos (infância, adolescência, adulto, gestantes e nutrizes, idosos e outros grupos específicos) e patologias específicas;

5. Princípios, métodos e técnicas de educação alimentar e nutricional aplicadas a coletividades e indivíduos;

6. Métodos e técnicas de comunicação e relacionamento inter-pessoal necessários para a relação com o indivíduo, comunidade e atuação na equipe multiprofissional.

\section{No domínio das habilidades: ao final do curso de graduação, o aluno deverá estar capacitado a:}

1. Acessar, selecionar e manejar informações;

2. Identificar, analisar e interpretar os problemas da saúde, alimentação e nutrição na prática profissional; 
116 | L.A.S. SANTOS et al.

3. Buscar, selecionar e integrar os conhecimentos necessários para as soluções dos problemas;

4. Utilizar a metodologia científica na aquisição e produção do conhecimento;

5. Utilizar o raciocínio investigativo clínico para a compreensão dos problemas e tomada de decisões;

6. Utilizar e manejar apropriadamente as técnicas, os instrumentos, procedimentos e outros recursos tecnológicos aplicados na prática profissional do nutricionista;

7. Utilizar de forma adequada os meios de comunicação verbal e não verbal nas relações de trabalho e no atendimento ao indivíduo e/ou coletividade;

8. Gerenciar, organizar, coordenar, liderar e capacitar equipes de trabalho da sua área de competência;

\section{No domínio das atitudes: ao final do curso de graduação, o aluno deverá estar capacitado a:}

1. Compreender o papel do exercício profissional como instrumento de promoção de transformações sociais;

2. Apropriar-se de novas formas de aprender, conectadas com a realidade concreta, aprimorando a independência intelectual, o exercício da crítica e a autonomia no aprender;

3. Desenvolver a atitude científica valorizando a produção e utilização do conhecimento científico-tecnológico, aprimorando o rigor científico e intelectual em suas ações sociais e profissionais;

4. Ter espírito empreendedor;

5. Aprimorar valores éticos e humanísticos essenciais para o exercício profissional tais como a solidariedade, respeito à vida humana, convivência com a pluralidade e diversidade de pensamento;

6. Assegurar o mais alto grau possível de qualidade na atenção prestada ao indivíduo e coletividade, com responsabilidade e compromisso;

7. Reconhecer os limites e as possibilidades da sua prática profissional;

8. Buscar constante aprimoramento profissional através da educação continuada 


\section{ANEXO 3}

\section{EIXOS TEMÁTICOS PROPOSTOS PARA O CURSO DE GRADUAÇÃO EM NUTRIÇÃO DA ENUFBA}

\section{Eixo Temático 1: Elementos essenciais que permeiam o processo de formação do nutricionista}

1. Conceitos, métodos e técnicas do conhecimento e investigação científica;

2. Conceito de saúde, processo saúde e doença enquanto processo social;

3. A segurança alimentar;

4. Saúde e sociedade;

5. Processo de trabalho em nutrição;

6. Ética, bioética e princípios humanísticos.

\section{Eixo Temático 2: a Alimentação e Nutrição na promoção da saúde}

1. Processo de produção, distribuição e utilização biológica dos alimentos na sociedade;

2. Comportamento alimentar da sociedade e os seus determinantes;

3. Composição, propriedades e transformações dos alimentos;

4. Os principais processos tecnológicos aplicados no processo de preparo, armazenamento, processamento, controle, conservação, embalagem, distribuição e utilização dos alimentos e produtos alimentícios, bem como seu impacto: no valor nutricional dos alimentos, na biodisponibilidade dos nutrientes e na saúde humana.

5. Fenômeno do crescimento e desenvolvimento, do envelhecimento e em grupos específicos, tais como: mulher, trabalhador, atleta entre outros; considerando o processo saúde e doença;

6. O processo de digestão, absorção, metabolismo e excreção, bem como as funções dos nutrientes e outros produtos alimentares no organismo humano.

\section{Eixo Temático 3: compreensão do processo saúde-doença e sua interface com a alimentação e nutrição}

1. A produção e distribuição das doenças e dos distúrbios nutricionais das coletividades;

2. Processo saúde-doença nos diferentes estágios da vida e grupos sociais, e sua correlação com a alimentação e nutrição, e com os distúrbios nutricionais.

\section{Eixo Temático 4: a Alimentação e Nutrição na recuperação e manutenção da saúde.}

1. Conceitos, métodos e técnicas da investigação epidemiológica em saúde e nutrição;

2. Conceitos, métodos e técnicas da avaliação alimentar e nutricional no plano individual e coletivo;

3. Teorias, enfoques e métodos das políticas, estratégias e ações de saúde historicamente construídas para o enfrentamento dos problemas;

4. Teorias, enfoques e métodos das políticas, estratégias e ações de alimentação e nutrição historicamente construídas para o enfrentamento dos problemas;

5. Os elementos constitutivos do novo modelo de atenção à saúde preconizados para o enfrentamento dos desafios atuais;

6. Métodos e técnicas de administração e gerenciamento das ações de saúde bem como de serviços de alimentação e nutrição, levando em conta o processo de trabalho e o custo-efetividade;

7. Princípios, métodos e técnicas da dietoterapia aplicada aos diferentes grupos sociais: infância, adolescência, adulto e idoso; nos grupos específicos - mulher, trabalhador, atleta e nas patologias específicas - tais como hipertensão, obesidade, e diabetes;

8. Princípios, métodos e técnicas da educação alimentar e nutricional aplicados a coletividades, grupos sociais e indivíduos;

9. Métodos e técnicas de comunicação e relacionamento pessoal necessárias para a apropriada relação com os pacientes, grupos e comunidades e atuação em equipes multiprofissionais. 